\title{
Role of Serum Uric Acid in the Assessment of Stroke
}

\author{
Avapati Raja Sekhar ${ }^{1}$, Ravi Kiran Narukurthi², Siva Kumar B. ${ }^{3}$, Kiran Deedi M. ${ }^{4}$
}

${ }^{1}$ Department of General Medicine, GSL Medical College, Rajahmundry, Andhra Pradesh, India. ${ }^{2}$ Department of General Medicine, GSL Medical College, Rajahmundry, Andhra Pradesh, India. ${ }^{3}$ Department of General Medicine, GSL Medical College, Rajahmundry, Andhra Pradesh, India. ${ }^{4}$ Central Research Laboratory, GSL Medical College, Rajahmundry, Andhra Pradesh, India.

\section{ABSTRACT}

\section{BACKGROUND}

Hyperuricaemia may be associated with an increased risk of stroke, but updated results from several studies have been inconsistent. The present study aimed to evaluate the relationship between hyperuricaemia \& risk of stroke.

\section{METHODS}

This cross-sectional study was conducted in the Department of General Medicine, GSL Medical College and General Hospital, Rajamahendravaram, with a total of 144 stroke patients. Other risk factors were also noted and serum uric acid (SUA) levels were determined.

\section{RESULTS}

There was a significant $(\mathrm{p}<0.05)$ difference in the mean levels of different categories of age and increased levels of SUA levels in both males and females. There was a significant association between hypertension, diabetes mellitus, dyslipidaemia, CAD, but no significant relationship with $(\mathrm{p}>0.05)$ history of cerebrovascular accident (CVA), smoking and alcohol consumption. There was a significant association $(\mathrm{p}<0.05)$ between stratified SUA levels (normal and hyperuricaemia) and hypertension, diabetes mellitus, dyslipidaemia, coronary artery disease (CAD) and age, but no significant $(\mathrm{p}>0.05)$ association with history of CVA, smoking and alcohol consumption.

\section{CONCLUSIONS}

Elevated SUA level is a significant risk factor for stroke. elevated serum uric acid level needs to be interpreted carefully in patients with risk factors for vascular events like hypertension, diabetes mellitus, dyslipidaemia and a history of prior vascular events. The prevalence of hyperuricaemia was found to be high especially in patients in their seventh decade of life and later.

\section{KEY WORDS}

Stroke, Uric Acid, Gender, Stroke Risk Factors
Corresponding Author: Dr. Ravi Kiran Narukurthi, Associate Professor, Department of General Medicine, GSL Medical College, Rajahmundry, Andhra Pradesh, India. E-mail: gslcentralresearchlab@gmail.com

DOI: $10.14260 /$ jemds/2020/18

Financial or Other Competing Interests: None.

How to Cite This Article: Sekhar AR, Narukurthi RK, Kumar SB, et al. Role of serum uric acid in the assessment of stroke. J. Evolution Med. Dent. Sci. 2020;9 (02):81-85, DOI: 10.14260/jemds/2020/18

Submission 16-11-2019,

Peer Review 27-12-2019,

Acceptance 02-01-2020,

Published 13-01-2020.

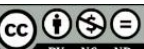




\section{BACKGROUND}

Stroke is the second most common cause of death and fourth leading cause of disability worldwide. Nearly 20 million people suffer from stroke each year and of these 5 million did not survive. In developed countries, stroke is the $1^{\text {st }}$ leading cause for disability, second leading cause of dementia and third leading cause of death. Stroke was the second-leading global cause of death behind heart disease in 2013, accounting for 11.8 percent of total deaths worldwide. Someone in the US has a stroke about every 40 seconds. ${ }^{1}$ Stroke also a predisposing factor for depression and epilepsy in developed countries and is a leading cause of functional impairments, with $20 \%$ of survivors requiring institutional care after 3 months and 15 to $30 \%$ being lifetime disabled. In low and middle-income countries stroke account for $85.5 \%$ of total stroke deaths worldwide and the number of disabilityadjusted life years in these countries was approximately seven times that in high-income countries.[1]

Worldwide there were 400-800 strokes per 100000 and 6.2 million deaths. Every year there were 16 million new acute strokes and 28,500,000 DALYs (Disability adjusted lifeyear). In India, prevalence rate was 90-222 strokes per $100000,1.44-1.64$ million cases of new acute strokes every year, 6398000 DALYs and $12 \%$ of strokes observed in the population aged $<40$ years. [1] Elevated SUA correlate with aging, male gender, hyperlipidaemia, diabetes mellitus, insulin resistance, glucose intolerance, obesity and hyperinsulinemia accelerate progression of hypertension and to end organ damage.[2] Higher levels of SUA were associated with a higher prevalence of carotid plaques which play an important role in the causation of ischemic cerebrovascular events in men.[3] The role of uric acid as an independent risk factor for vascular disease has remained questionable despite enough evidence to suggest that an elevated SUA may predict an increased risk of cardiovascular events including strokes. This study aimed to evaluate serum uric acid levels in patients with acute ischemic stroke and the association of uric acid level with the various risk factors of stroke.

\section{METHODS}

This cross-sectional study was conducted in the department of General Medicine, GSL Medical College and General Hospital, Rajamahendravaram. This study was approved by institutional ethical committee. Total 144 stroke patients, confirmed by imaging with CT/MRI brain after thorough history taking and neurological examination were included in the study. Sample size was taken based on the convenience of the study. Patients with renal failure, on long term diuretic therapy, suffering from malignancies and known cases of gout were excluded. Information regarding the risk factors for stroke such as smoking, alcohol consumption, hypertension, diabetes mellitus, dyslipidaemia, previous history of coronary artery disease, or an ECG evidence of CAD upon admission, or echocardiography evidence of regional wall motion abnormalities was obtained and recorded. Two millilitres of blood were taken into vial without anticoagulant, within the first 24 hours of hospital admission of stroke patients. Serum uric acid concentration was estimated by enzymatic method. Uric acid in presence of uricase, oxidised to allantoin with liberation of hydrogen peroxide. The peroxide reacts with 4-amino-antipyrine (4AAP) and 3, 5-dichloro-2-hydroxybenzene sulfonic acid in the presence of peroxidase to form a quinone imine dye. The absorbance of this dye read at $505 \mathrm{~nm}$ which is proportional to concentration of uric acid in the sample.[4]

\section{Statistical Analysis}

Data was expressed as mean \pm standard deviation (SD). Unpaired t- test and ANOVA were used to compare the differences between means of quantitative variables. Chisquare test was used to know association between variables. $p<0.05$ was considered as statistically significant. All the Statistical analysis was performed using SPSS trail version 21.

\section{RESULTS}

The study comprised of 144 stroke subjects between 18 and 85 years of age. There was a significant $(p<0.05)$ difference in the mean of different categories of age and increased uric acid levels in both males and females as on age progresses particularly in males (Table 1).

\begin{tabular}{|c|c|c|c|c|c|c|c|}
\hline \multirow[b]{2}{*}{ Gender } & \multicolumn{6}{|c|}{ Age (Year) } & \multirow[b]{2}{*}{ p Value } \\
\hline & \begin{tabular}{|c|}
$>40$ \\
$(n=16)$
\end{tabular} & $\begin{array}{l}41-49 \\
(n=24)\end{array}$ & \begin{tabular}{|l|}
$50-59$ \\
$(n=31)$ \\
\end{tabular} & $\begin{array}{l}60-69 \\
(n=42)\end{array}$ & \begin{tabular}{|l|}
$\begin{array}{l}70-79 \\
(n=26)\end{array}$ \\
\end{tabular} & $\begin{array}{c}>80 \\
(n=5)\end{array}$ & \\
\hline Male & $3.1 \pm 0.5$ & $5.0 \pm 1.4$ & $4.8 \pm 1.4$ & $5.8 \pm 1.1$ & $7.1 \pm 1.3$ & $8.2 \pm 0.5$ & 0.001 \\
\hline Female & $3.4 \pm 0.6$ & $4.2 \pm 0.7$ & $5.1 \pm 1.9$ & $5.1 \pm 1.8$ & $6.8 \pm 1.9$ & 6.8 & 0.001 \\
\hline \multicolumn{8}{|c|}{$\begin{array}{c}\text { Table 1. Mean } \pm \text { SD of Uric Acid Levels Regarding Stratified } \\
\text { Age Intervals in Male and Female Stroke Subjects }\end{array}$} \\
\hline & wha & $\mathrm{an}+\mathrm{SD}$ & & & er of subis & & \\
\hline
\end{tabular}

\begin{tabular}{|c|c|c|c|}
\hline Uric Acid (mg/dl) & Males $(n=86)$ & Female $(n=58)$ & p Value \\
\hline$<5$ & $38(44.2 \%)$ & $38(65.5 \%)$ & \multirow{3}{*}{0.024} \\
\hline $5-6.9$ & $24(27.9 \%)$ & $7(12.1 \%)$ & \\
\hline$\geq 7$ & $24(27.9 \%)$ & $13(22.4 \%)$ & \\
\hline \multicolumn{4}{|c|}{$\begin{array}{l}\text { Table 2. Association of Clinical Characteristics with Stratified } \\
\text { Uric Acid Intervals in Male and Female Stroke Patients }\end{array}$} \\
\hline \multicolumn{4}{|c|}{$\begin{array}{l}\text { Data were shown as the number and percentage }(\%) \text {; ' } n \text { ' represents number of } \\
\text { subjects; p value was calculated by chi-square test; } p<0.05 \text { was considered as } \\
\text { statistically significant. }\end{array}$} \\
\hline
\end{tabular}

\begin{tabular}{|c|c|c|c|c|}
\hline Characteristic & Status & Males $(n=86)$ & $\begin{array}{l}\text { Female } \\
(n=58)\end{array}$ & p Value \\
\hline \multirow{2}{*}{ Hypertension } & Yes (102) & $6.25 \pm 1.5$ & $5.55 \pm 1.7$ & 0.001 \\
\hline & No (42) & $4.07 \pm 1.2$ & $3.75 \pm 0.8$ & 0.001 \\
\hline \multirow{2}{*}{ Diabetes mellitus } & Yes (70) & $6.69 \pm 1.4$ & $5.82 \pm 1.7$ & 0.001 \\
\hline & No (74) & $4.68 \pm 1.4$ & $4.16 \pm 1.1$ & 0.001 \\
\hline \multirow{2}{*}{ Dyslipidaemia } & Yes (68) & $6.45 \pm 1.7$ & $6.01 \pm 1.8$ & 0.001 \\
\hline & No (76) & $4.87 \pm 1.4$ & $4.08 \pm 1.0$ & 0.001 \\
\hline \multirow{2}{*}{ CAD } & Yes (32) & $6.95 \pm 1.8$ & $6.25 \pm 2.0$ & 0.001 \\
\hline & No (112) & $5.30 \pm 1.6$ & $4.55 \pm 1.4$ & 0.001 \\
\hline \multirow{2}{*}{ CVA } & Yes (06) & $6.70 \pm 1.0$ & $4.90 \pm 0.9$ & 0.20 \\
\hline & No (138) & $5.53 \pm 1.7$ & $5.05 \pm 1.8$ & 0.90 \\
\hline \multirow{2}{*}{ Smoking } & Yes (70) & $5.76 \pm 1.8$ & $6.2 \pm 2.3$ & 0.11 \\
\hline & No (74) & $5.08 \pm 1.4$ & $4.91 \pm 1.6$ & 0.08 \\
\hline \multirow{2}{*}{$\begin{array}{c}\text { Alcohol } \\
\text { consumption }\end{array}$} & Yes (71) & $5.66 . \pm 1.7$ & $5.76 \pm 2.1$ & 0.50 \\
\hline & No (73) & $5.36 \pm 1.6$ & $4.98 \pm 1.7$ & 0.35 \\
\hline \multicolumn{5}{|c|}{$\begin{array}{c}\text { Table 3. Mean } \pm \text { SD of Uric Acid in Different Characteristics of } \\
\text { Male and Female Stroke Subjects }\end{array}$} \\
\hline
\end{tabular}

There was a significant $(\mathrm{p}<0.05)$ association was observed between stratified levels of uric acid with gender 
and higher number of stroke patients with hyperuricaemia were in males (Table 2). There was significant $(p<0.05)$ difference in mean levels of uric acid in both male and female stroke subjects with or without hypertension, with or without diabetes mellitus, with or without dyslipidaemia, with or without CAD, but no significant ( $p>0.05$ ) difference in means of uric acid in both male and female stroke subjects with or without history of CVA with or without smoking, with or without alcohol consumption (Table 3). There was significant $(\mathrm{p}<0.05)$ association was observed between stratified uric acid levels (normal and hyperuricaemia) and hypertension, diabetes mellitus, dyslipidaemia, CAD and age, but no significant ( $p>0.05$ ) association with CVA, smoking and alcohol consumption (Table 4).

\begin{tabular}{|c|c|c|c|c|}
\hline Characteristic & Status & $<7 \mathrm{mg} / \mathrm{dl}(\mathrm{n}=110)$ & $\begin{array}{c}>7 \mathrm{mg} / \mathrm{dl} \\
(\mathrm{n}=34)\end{array}$ & $\mathbf{p}$ \\
\hline \multirow{2}{*}{ Hypertension } & Yes (102) & $69(62.7 \%)$ & $33(97.1 \%)$ & \multirow{2}{*}{0.001} \\
\hline & No (42) & $41(37.3 \%)$ & $1(2.9 \%)$ & \\
\hline \multirow{2}{*}{ Diabetes mellitus } & Yes (70) & $43(39.1 \%)$ & $27(79.4 \%)$ & \multirow{2}{*}{0.001} \\
\hline & No (74) & $67(60.9 \%)$ & $7(20.6 \%)$ & \\
\hline \multirow{2}{*}{ Dyslipidaemia } & Yes (68) & $41(37.3 \%)$ & 27 (79.4\%) & \multirow{2}{*}{0.001} \\
\hline & No (76) & $69(62.7 \%)$ & $7(20.6 \%)$ & \\
\hline \multirow{2}{*}{ CAD } & Yes (32) & $16(14.5 \%)$ & $16(47.1 \%)$ & \multirow{2}{*}{0.001} \\
\hline & No (112) & $94(85.5 \%)$ & $18(52.9 \%)$ & \\
\hline \multirow{2}{*}{ CVA } & Yes (06) & $4(3.6 \%)$ & $2(5.9 \%)$ & \multirow{2}{*}{0.567} \\
\hline & No (138) & $106(96.4 \%)$ & $32(94.1 \%)$ & \\
\hline \multirow{2}{*}{ Smoking } & Yes (70) & $49(44.5 \%)$ & $21(61.8 \%)$ & \multirow{2}{*}{0.079} \\
\hline & No (74) & $61(55.5 \%)$ & $13(38.2 \%)$ & \\
\hline \multirow{2}{*}{$\begin{array}{c}\text { Alcohol } \\
\text { consumption }\end{array}$} & Yes (71) & $52(47.3 \%)$ & $19(55.9 \%)$ & \multirow{2}{*}{0.380} \\
\hline & No (73) & $58(52.7 \%)$ & 15 (44.1\%) & \\
\hline \multirow{2}{*}{ Age } & $\begin{array}{c}<65 \text { years } \\
(100)\end{array}$ & $0 \%)$ & 12 & \multirow{2}{*}{0.001} \\
\hline & $\begin{array}{c}>65 \text { years } \\
(44)\end{array}$ & $22(20 \%)$ & $22(64.7 \%)$ & \\
\hline
\end{tabular}

Table 4. Association of Clinical Characteristics with Stratified Uric Acid Intervals

Data were shown as the number and percentage (\%); ' $n$ ' represents number of subjects; $p$ value was calculated by chi-square test; $p<0.05$ was considered as statistically significant.

\section{DISCUSSION}

The present study was aimed to evaluate SUA levels in patients with acute ischemic stroke and to study its association with risk factors for stroke. The study has included 144 subjects with acute ischemic stroke. In the present study there was significant relationship was shown between uric acid and age, as age increases the level of SUA increases in both male and females similar results were also observed in cross sectional study conducted with acute stroke patients in Firoozgar Hospital,[5] and uric acid levels were higher in males than in females as, in study conducted with 163 individuals, admitted due to a first-ever-in-alifetime acute ischemic/non-embolic stroke and 166 volunteers without a history of CV disease, ${ }^{[6]}$ study conducted in eastern part of India,[7] in cross-sectional study with 60 cases of acute ischemic stroke ${ }^{[8]}$ and also in noninterventional prospective study conducted among 100 cases of acute ischemic stroke.[9]

Elevation in SUA levels may be due to increased synthesis of UA, decreased excretion of UA and mixed type. It could be due to incidence of each type varies depending on the target population considered, since SUA concentrations are influenced by many factors such as alcohol consumption, nutrition, renal function and genetic factors. Milionis et al., reported that elevated SUA is related with an increased risk for non-embolic/ acute ischemic stroke in a firmly defined population of elder individuals independently of concomitant metabolic derangements. This association may consider when treating the elderly individuals.[6] The SUA concentration in adult women, which were lower than in men of a similar age, it could be related to a higher renal clearance of uric acid in women, possibly due to higher oestrogen levels in their plasma.[10] In this study significant relation was observed between uric acid and hypertension this results was consistent with a study conducted with 297 individuals from Cameroon population,[11] in study with 163 individuals more than 70 years of age admitted in hospital due to a first time ever acute ischemic/ non-embolic stroke and 166 volunteers without a history of cardiovascular disease in Greece, ${ }^{[6]}$ study with 1920 adults from Romanian adult population,[12] and also a cohort study from china with 1082 healthy participants aged 41 to 70 years.[13]

A meta-analysis and systematic review concluded that 1.0 $\mathrm{mg} / \mathrm{dl}$ increase in SUA level is associated with an increased risk of incident hypertension by $13 \% .{ }^{[14]}$ Uric acid could play a role in the pathogenesis of early onset hypertension [15] but the levels may tend to reduce with age where stiffening of the aorta, activation of the renin-angiotensin system and renal vasoconstriction have a role to play.[16] However, Teng et al, reported that converse result where in uric acid was associated with the risk of hypertension in the elderly.[16] Triglycerides have been linked to insulin resistance which accelerates hypertension through renal tubular sodium reabsorption, augmentation of the sympathetic nervous system reactivity and activation of the renin-angiotensin system.[17] Uric acid can also induce the renin-angiotensin system it is possible that they both have an additive effect on the blood pressure response.

In this study significant relationship was observed between uric acid and dyslipidaemia similar results were also found in cross sectional study conducted with acute stroke patients Firoozgar Hospital,[5] cross-sectional study with 60 cases of acute ischemic stroke, ${ }^{[8]}$ retrospective and crosssectional, longitudinal component, the database of the lipid clinic, Mubarak Al-Kabeer hospital, Kuwait,[18] a study group comprised of 100 newly detected type 2 diabetic patients in the age group of 30-60 years control group 100 age and sex matched healthy participants,[19] a cross-sectional study conducted with 280 general adult participants recruited from university staff, university students, city people and individuals who went to the local clinic for the routine health check-up in Sylhet and Dhaka cities of Bangladesh. ${ }^{[20]}$ Elevated SUA levels were significantly found among those with dyslipidaemia with high triglycerides.[21]

In this study significant relationship was observed between uric acid and diabetes mellitus this result was consistent with study in T2D duration $<2$ years at baseline in the treatment options for type 2 diabetes in adolescents and youth study[22] but in contrast, a significant inverse association was observed between the levels of SUA and diabetes in Bangladeshi adults.[23] The increased serum uric acid level was also found to be associated with the severity of CAD in both men and women. In the present study significant relationship was observed between uric acid and CAD similar results were reported from a study with 1012 patients who underwent coronary angiography in Turkish population,[24] cross-sectional retrospective study included 607 
premenopausal women who had undergone coronary angiography[25] and also in hospital-based case-control study conducted in patients attending the affiliated hospital of Qingdao university, China.[26]

Hyperuricaemia predisposes to the progress of hypertension and oxidative stress may increase and generates free radicals, which eventually acts as source of future cardiovascular disease risk. [27] Kim et al., conducted a large systemic review and meta-analysis known to date investigating the relationship of stroke and hyperuricaemia, from sixteen prospective cohort studies, over 230,000 patients with hyperuricaemia were found to be at a significantly higher risk for both stroke incidence and mortality than controls with normal uric acid levels. [28] Holme et al reported that uric acid could be as a potential risk factor for congestive heart failure, acute myocardial infarction and stroke in the apolipoprotein mortality risk study and concluded that uric acid levels were found to be associated with increased risk of both ischemic and hemorrhagic stroke.[29]

\section{CONCLUSIONS}

Elevated SUA level is a significant risk factor for stroke. elevated serum uric acid level needs to be interpreted carefully in patients with risk factors for vascular events like hypertension, diabetes mellitus, dyslipidaemia and a history of prior vascular events. The prevalence of hyperuricaemia was found to be high especially in patients in their seventh decade of life and later.

\section{ACKNOWLEDGEMENT}

Authors thank the management of GSL Medical College and General Hospital, Rajamahendravaram, Andhra Pradesh, India, all patients participated in the study and also the technicians of Department of Biochemistry, GSL Medical College and General Hospital.

\section{REFERENCES}

[1] Taylor FC, Kumar SK. Stroke in India - Factsheet (Updated 2012). South-Asian Network for Chronic Diseases

(SANCD). https://www.sancd.org/Updated\%20Stroke\%20Fact\%2 0sheet\%202012.pdf

[2] Alexander S, Bernard T. Uric acid transport and disease. J Clin Invest 2010;120 (6):1791-9.

[3] Logallo N, Naess H, Idicula TT, et al. Serum uric acid: neuroprotection in thrombolysis. The Bergen NORSTROKE Study. BMC Neurology 2011;11:114.

[4] Zhao Y, Yang X, Lu W, et al. Uricase based methods for determination of uric acid in serum. Microchimica Acta 2009;164:1-6

[5] Mehrpour M, Khuzan M, Najimi N, et al. Serum uric acid level in acute stroke patients. Med J Islam Repub Iran 2012;26 (2):66-72.
[6] Milionis HJ, Kalantzi KJ, Goudevenos JA, et al. Serum uric acid levels and risk for acute ischaemic non-embolic stroke in elderly subjects. J Intern Med 2005;258 (5):435-41.

[7] Behera BK, Hui PK, Simethy R. Serum uric acid level in acute ischemic stroke in eastern India. Int J Res Med Sci 2017;5 (6):2353-7.

[8] Arora T, Mantur PG, Bidri RC, et al. Serum uric acid levels and serum lipid levels in patients with ischemic cerebrovascular accident. J Assoc Physicians India 2018;66 (7):66-8.

[9] Harsh S, Aparna P. The study of serum uric acid levels in ischemic stroke patients. IJCMR 2019;6 (1):A16-A20.

[10] Antón FM, Puig JG, Ramos T, et al. Sex differences in uric acid metabolism in adults: evidence for a lack of influence of estradiol- $17 \beta\left(\mathrm{E}_{2}\right)$ on the renal handling of urate. Metabolism 1986;35 (4):343-8.

[11] Assob JCN, Ngowe MN, Nsagha DS, et al. The relationship between uric acid and hypertension in adults in Fako division, SW Region Cameroon. J Nutr Food Sci 2014;4:257.

[12] Buzas R, Tautu OF, Dorobantu M, et al. Serum uric acid and arterial hypertension-Data from Sephar III survey. PLoS One 2018;13 (7):e0199865.

[13] Cheng W, Wen S, Wang Y, et al. The association between serum uric acid and blood pressure in different age groups in a healthy Chinese cohort. Medicine (Baltimore) 2017;96 (50):e8953.

[14] De Becker B, Borghi C, Burnier M, et al. Uric acid and hypertension: an update. Scientific Newsletter Update on Hypertension Management 2018;19:69.

[15] Sica DA. The kidney and hypertension: causes and treatment. J Clin Hypertens (Greenwich) 2008;10 (7):541-8.

[16] Teng F, Zhu R, Zou C, et al. Interaction between serum uric acid and triglycerides in relation to blood pressure. J Hum Hyperten 2011;25 (11):686-91.

[17] Mazzali M, Hughes J, Kim YG, et al. Elevated uric acid increases blood pressure in the rat by a novel crystalindependent mechanism. Hypertension 2001;38 (5):1101-6.

[18] Al-Meshaweh AF, Jafar Y, Asem M, et al. Determinants of blood uric acid levels in a dyslipidemic Arab population. Med Princ Pract 2012;21 (3):209-16.

[19] Doddamani S, Veni U. Association of uric acid and dyslipidaemia in newly detected type 2 Diabetes Mellitus. JMSCR 2019;7 (9):222-6.

[20] Ali N, Rahman S, Islam S, et al. The relationship between serum uric acid and lipid profile in Bangladeshi adults. BMC Cardiovas Disord 2019;19 (1):42.

[21] Rao TMV, Vanukuri NK. A study on serum uric acid levels in type 2 diabetes mellitus and its association with cardiovascular risk factors. IAIM 2016;3 (12):148-55.

[22] Bjornstad P, Laffel L, Lynch J, et al. Elevated serum uric acid is associated with greater risk for hypertension and diabetic kidney diseases in obese adolescents with type 2 diabetes: an observational analysis from the Treatment Options for Type 2 Diabetes in Adolescents and Youth (TODAY) Study. Diabetes Care 2019;42 (6):1120-8. 
[23] Haque T, Rahman S, Islam S, et al. Assessment of the relationship between serum uric acid and glucose levels in healthy, prediabetic and diabetic individuals. Diabetol Metab Syndr 2019;11:49.

[24] Deveci OS, Kabakci G, Okutucu S, et al. The association between serum uric acid level and coronary artery disease. Int J Clin Pract 2010;64 (7):900-7.

[25] Zhang JW, He LJ, Cao SJ, et al. Association of serum uric acid and coronary artery disease in premenopausal women. PLoS One 2014;9 (9):e106130.

[26] Tian TT, Li H, Chen SJ, et al. Serum uric acid as an independent risk factor for the presence and severity of early-onset coronary artery disease: a case-control study. Disease Markers 2018;2018:1236837.
[27] Baldwin W, McRae S, Marek G, et al. Hyperuricaemia as a mediator of the proinflammatory endocrine imbalance in the adipose tissue in a murine model of the metabolic syndrome. Diabetes 2011;60 (4):1258-69.

[28] Kim SY, Guevara JP, Kim KM, et al. Hyperuricemia and risk of stroke: a systematic review and meta-analysis. Arthritis and Rheumatism 2009;61 (7):885-92.

[29] Holme I, Aastveit AH, Hammar N, et al. Uric acid and risk of myocardial infarction, stroke and congestive heart failure in 417,734 men and women in the apolipoprotein mortality risk study (AMORIS). J Intern Med 2009:266 (6)558-70. 